УДК

\title{
КОМПАКТНАЯ ТРЕХДИАПАЗОННАЯ АНТЕННА С КОПЛАНАРНЫМ ПИТАНИЕМ И ДЕФЕКТНОЙ СТРУКТУРОЙ ЭКРАНА ДЛЯ GSM, WLAN И WIMAX
}

\author{
БОРА ДЖ. ${ }^{* *}$, ШЕЙХ Т. А. ${ }^{1 * *}$, РОЙ С. ${ }^{2 * * *}$ \\ ${ }^{1}$ Северо-восточный региональный институт науки и техники, \\ Индия, Нирджули, 791109, Аруначал-Прадеш \\ ${ }^{2}$ Национальный технологический институт, \\ Индия, Аруначал-Прадеш, 791112
}

\begin{abstract}
Аннотация. В статье предложена и исследована оригинальная компактная трехдиапазонная антенна с копланарным питанием на подложке из диэлектрика FR4, которая предназначена для приложений беспроводной связи. В своем составе антенна имеет частотно-сдвигающие полоски и дефектную структуру экрана, образованную путем объединения металлических полос и вырезания L-образной щели в экране. Предложенная антенна обеспечивает три различные полосы пропускания, определяемые по входному импедансу, а именно 0,57, 0,98 и 1,59 ГГц, которые достаточны для перекрытия частотных диапазонов стандартов GSM 1800/1900, WLAN 5,5/5,8 ГГц и WiMAX. Разработанная антенна имеет габариты $17 \times 20$ мм и работает в диапазонах частот 1,50-2, $08,5,25-6,23$ и 9, 10-10,69 ГГц, резонансные частоты которых составляют 1,702, 5,802 и 10,102 ГГц, соответственно. Антенна разработана и смоделирована с помощью программного обеспечения Ansoft HFSS. Рассчитаны коэффициент отражения, диаграмма направленности, полоса пропускания, определяемая по входному импедансу, и КСВН антенны.
\end{abstract}

Ключевые слова: питание с помощью копланарного волновода; CPW; FR-4; частотно сдвигающие полоски; FSS; дефектная структура экрана; DGS; трехдиапазонная антенна; GSM; WLAN; WiMAX

\section{1. ВВЕДЕНИЕ}

Планарная монопольная антенна широко используется благодаря своим хорошим характеристикам, включающим эффективное излучение, простоту изготовления, широкую полосу частот и низкую стоимость. Значительное количество исследований антенны этого типа посвящено объединению нескольких стандартов связи в одной беспроводной системе. В последнее время применение сверхширокополосного (СШП) и WLAN стандартов (Wi-Fi и WiMAX) привело к широкому использованию планарных монопольных антенн в беспроводных сетях.

Как правило, антенна меньших размеров имеет значительные ограничения такие, как низкий коэффициент усиления и узкая полоса пропускания, следовательно, при проектировании должны быть уменьшены или рабочий диапазон частот, или коэффициент усиления антенны. Существует несколько способов подачи питания, которые используются в монопольной антенне, а именно: питание с помощью зонда [1-4], питание микрополоском [5-7] и питание с помощью копланарного волновода CPW (coplanar waveguide) [8-10].

В данной работе предложена компактная трехдиапазонная антенна с копланарным питанием, которая состоит из частотно сдвигающих полосок FSS (frequency shifting strip) для обеспечения двухчастотной работы и L-образ- 